\title{
Attention and spatial selection: Electrophysiological evidence for modulation by perceptual load
}

\author{
TODD C. HANDY \\ Dartmouth College, Hanover, New Hampshire. \\ and \\ GEORGE R. MANGUN \\ Duke University, Durham, North Carolina
}

\begin{abstract}
Behavioral data have suggested that perceptual load can modulate spatial selection by influencing the allocation of attentional resources at perceptual-level processing stages (Lavie \& Tsal, 1994). To directly test this hypothesis, event-related potentials (ERPs) were recorded for both low- and highperceptual-load targets in a probabilistic spatial cuing paradigm. The results from three experiments showed that, as measured by the lateral occipital P1 and N1 ERP components, the magnitude of spatially selective processing in extrastriate visual cortex increased with perceptual load. Furthermore, these effects on spatial selection were found in the P1 at lower levels of perceptual load than in the N1. The ERP data thus provide direct electrophysiological support for proposals that link perceptual load to early spatial selection in visual processing. However, our findings suggest a relatively broader model-where perceptual load is but one of many factors mediating early selection.
\end{abstract}

By modulating the flow of sensory information in the brain, selective attention serves as the arbiter between perception and action in the natural environment (e.g., Cowan, 1995; Desimone \& Duncan, 1995; LaBerge, 1995; Pashler, 1998). In vision, selection can occur within a spatial frame of reference, with stimuli in attended spatial locations receiving preferential processing relative to stimuli occurring in unattended spatial locations (e.g., Näätänen, 1992). For example, manual responses to nonfoveal visual targets are quicker and more accurate when the target is presented at an attended visual field location than when the target is presented at an unattended visual field location (e.g., Bashinski \& Bacharach, 1980; Briand \& Klein, 1987; Downing, 1988; Handy, Kingstone, \& Mangun, 1996; Hawkins et al., 1990; Posner, 1980). The facilitatory effects of spatial attention on behavioral performance have been modeled by attentional resource the-

This research was supported by grants from NIMH and NINDS to G.R.M. and a University of California, Davis graduate research award to T.C.H. These experiments were conducted as part of the doctoral dissertation of the first author. The data from Experiment 1 and portions of the data from Experiment 3 were originally presented in March 1997 at the Fourth Annual Meeting of the Cognitive Neuroscience Society, Boston. The authors are grateful to Valerie Clark, Jennifer Isele, and Rita Kapoor for their help with data collection in Experiment 1, and to Jon Hansen and Clif Kussmaul for their technical support. We thank Art Kramer, Jeff Miller, Steve Hillyard, and an anonymous reviewer for helpful comment and discussion. Correspondence should be addressed to T. C. Handy, Center for Cognitive Neuroscience, Dartmouth College, 6162 Moore Hall, Hanover, NH 03755-3547 (e-mail: todd.c.handy@) dartmouth.edu).

-Accepted by previous editor, Myron L. Braunstein ory, which stipulates that the degree of processing for a given stimulus increases proportionally with the amount of attentional "resources" allocated to the location of the stimulus (e.g., Luck, Hillyard, Mouloua, \& Hawkins, 1996; Mangun \& Hillyard, 1990; Müller \& Humphreys, 1991; see also Cheal \& Gregory, 1997; Shiu \& Pashler, 1994). By assuming that attentional resources are limited in capacity (see Moray, 1967), spatial selection then arises because resource availability constrains which subset of sensory information will be preferentially processed at and beyond the locus of selection (e.g., Anllo-Vento \& Hillyard, 1996; Eimer, 1995; Hillyard \& Münte, 1984).

Lavie and Tsal (1994) have proposed that spatial selection is directly dependent on perceptual load, or the demand a given task places on attentional resources at perceptual-level processing stages. Perceptual load has its conceptual roots in capacity theories of attention (see Kramer \& Spinks, 1991) and is premised on the position that performing an experimental task activates a series of functionally discrete processing stages, spanning from initial sensory input to ultimate motor and/or cognitive output (e.g., Sanders, 1990; van der Molen, Bashore, Halliday, \& Callaway, 1991). According to capacity theory, attentional resources can be allocated to these different processing stages, with the demand for resources at any stage varying as a function of both stimulus and task parameters (e.g., Navon \& Gopher, 1979, 1980; Norman \& Bobrow, 1975; Wickens, 1980). However, the effects of attention differ across the functionally distinct stages, depending directly on the unique processing operation performed at each stage. Within this context, Lavie and Tsal (1994) argued that the spatially selective allocation of attentional resources occurs at perceptual-level processing 
stages, but only when the perceptual load of the given task is relatively high.

Support for Lavie and Tsal (1994) has come primarily from behavioral studies using distractor interference-type paradigms. In distractor paradigms, the depth of processing of a task-irrelevant distractor item (presented parafoveally) is measured by the degree to which it interferes with responding to task-relevant information at fixation. If the distractor is within a spatially attended region, it will create more response interference than if it is outside the attended region (e.g., Eriksen \& St. James, 1986; Eriksen \& Yeh, 1985; Pan \& Eriksen, 1993). According to Lavie and Tsal (1994), when a subject performs a distractor task under conditions of high perceptual load, all attentional resources are presumably committed to processing the task-relevant information, and spatial attention is narrowly focused at fixation. Assuming the demands on attentional resources have exceeded capacity limits, no residual resources remain to allocate to nonfoveal locations, and all task-irrelevant information is excluded from higher level processing - the signature of spatial selection in distractor paradigms. However, if perceptual load is reduced and the demand for attentional resources falls significantly below capacity limits, only a portion of the available resources are necessary for processing task-relevant information. Lavie and Tsal proposed that the residual resources will then be automatically allocated to processing task-irrelevant information. Under these reduced-load conditions, with spatial attention more broadly distributed, no evidence for early selection will be found because information both relevant and irrelevant to the task is processed at perceptual-level stages (e.g., Dark, Johnston, Myles-Worsley, \& Farah, 1985; Kahneman \& Chajczyk, 1983; Lavie, 1995; Lavie \& Cox, 1997; Miller, 1991; Yantis \& Johnston, 1990; see also Wojciulik, Kanwisher, \& Driver, 1997).

While Lavie and Tsal (1994) provide a cogent account of the data from distractor interference studies, the deeper implication of their model remains untested: Are the effects of perceptual load on spatial selection truly occurring at relatively early, perceptual-level processing stages? The behavioral data from distractor studies provide no direct supporting evidence, raising the possibility that purported manipulations of "perceptual load" may actually reflect selection at later, postperceptual processing stages (cf. Sperling, 1984; Sperling \& Dosher, 1986). To resolve this issue, we used event-related potentials (ERPs) to directly examine spatially selective processing in early visual cortex under conditions of low and high perceptual load.

\section{EXPERIMENT 1}

The sensory-evoked P1 and N1 ERP components have been shown to be larger for stimuli presented in attended spatial locations than in unattended spatial locations (e.g., Eason, 1981; Eason, Harter, \& White, 1969; Heinze,
Luck, Mangun, \& Hillyard, 1990; Heinze, Luck, et al., 1994; Van Voorhis \& Hillyard, 1977; for reviews, see Mangun, 1995; Mangun \& Hillyard, 1995). Subsequent research combining ERPs and functional neuroimaging have localized the generators of the $\mathrm{P} 1$ and $\mathrm{N} 1$ to extrastriate visual cortex, suggesting a relatively early locus of spatial attention effects in visual processing (Clark, Fan, \& Hillyard, 1995; Clark \& Hillyard, 1996; Heinze, Mangun, et al., 1994; Mangun, Hopfinger, Kussmaul, Fletcher, \& Heinze, 1997). The amplitudes of the Pl and N1 have also been shown to increase with the amount of attentional resources voluntarily allocated to the spatial location of the ERP-eliciting stimulus (Mangun \& Hillyard, 1990; see also Alho, Woods, Algazi, \& Näätänen, 1992). If perceptual load can modulate spatial selection at relatively early, perceptual-level processing stages by influencing the allocation of attentional resources, the $\mathrm{Pl}$ and $\mathrm{N} 1$ attention effects should be sensitive to manipulations of perceptual load. This possibility could provide a theoretical basis for why some ERP cuing studies have found attention effects in the $\mathrm{Pl}$ and N1 (e.g., Luck et al., 1994; Mangun \& Hillyard, 1991) whereas others have not (e.g., Eimer, 1994) - the perceptual load of the targets in the former studies may have been significantly higher than in the latter, thereby leading to a greater concentration of attentional resources at the cued location.

To test the predicted effects of perceptual load on attentional resource allocation, we varied load in a spatial cuing task. On each trial, subjects made a letter discrimination judgment for a nonfoveal target that was presented in either a cued (more likely) location or an uncued (less likely) location. Under conditions of low perceptual load, the target letters were easily discriminable, whereas under conditions of high load, the targets were relatively difficult to discriminate (i.e., they were highly similar; see Duncan \& Humphreys, 1989, 1992). ERPs to target stimuli were recorded as a function of perceptual load (low vs. high) and location expectancy (cued vs. uncued location). If perceptual load can affect early selection by modulating the amount of resources allocated to an attended location, the expectancy (or attention) effect should be larger under conditions of high perceptual load than under conditions of low perceptual load.

\section{Method}

Subjects. Twelve members ( 8 females, 4 males) of the University of California, Davis, community between the ages of 20 and 29 years were recruited as paid subjects. One subject was left-handed, and all had normal or corrected-to-normal vision.

Apparatus and Stimuli. Stimuli were presented on a 15-in. NEC 4FG color monitor placed $100 \mathrm{~cm}$ from the subject and controlled by a 486-based microcomputer using VGA graphics. Stimulus sequence and timings are shown in Figure 1. Each trial began with the presentation of an arrow at fixation that cued either the left or the right target location. The cue was followed, after a brief delay, by a target letter at either the cued or the uncued location.

The cue was a green $0.7^{\circ}$-long arrow presented $0.2^{\circ}$ above fixation. The target letters (" $\mathrm{A}$ " and " $\mathrm{H}$ ") were drawn with white lines $0.06^{\circ}$ thick and were $0.86^{\circ}$ wide $\times 0.86^{\circ}$ tall. The target letters were 
LOW LOAD TRIAL

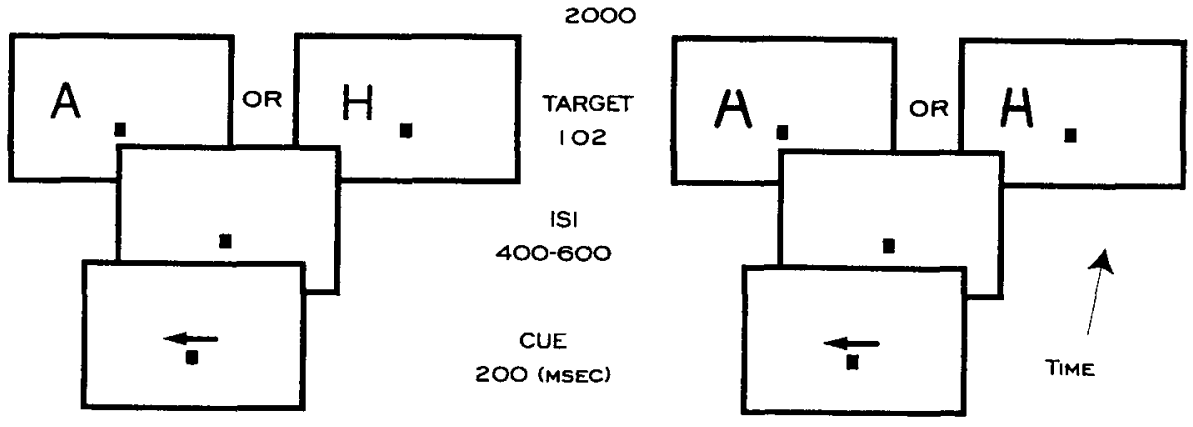

Figure 1. Sequence and timing of stimulus events presented on each trial in Experiment 1, as a function of perceptual load condition. Stimuli are drawn in reverse contrast to that used in the actual experiment and are not to scale. A valid trial to the left is shown. In the high-load condition, three pairs of increasingly similar letters were actually used in order to equalize performance across subjects (see text).

presented $5.4^{\circ}$ to center from fixation in either the right or the left visual field and were $0.86^{\circ}$ to center above the horizontal meridian. In the low-load condition, the target letters were normal As and Hs. In the high-load condition, the target letters were made more similar by pulling apart the arms of the $A$ and bending in the arms of the $H$. To accommodate variability in the subjects' ability to make the discrimination in the high-load condition, three pairs of target letters were used that had increasingly similar distances between the arms of the letters (depending on subject performance; see below). In the easiest of the three pairs, the A had a gap of $0.23^{\circ}$ at the top between the arms and the top of the $H$ was narrowed to $0.52^{\circ}$. In the medium difficulty pair, the $A$ gap was $0.28^{\circ}$ and the $H$ gap was $0.46^{\circ}$. In the most difficult pair, the A gap was $0.34^{\circ}$ and the $\mathrm{H}$ gap was $0.40^{\circ}$ (see Figure 1).

Procedure. The task required a forced, two-choice decision regarding the identity of the target stimulus on each trial. The subjects responded by pressing the appropriate response button " $\mathrm{A}$ " with one thumb, " $H$ " with the other thumb, counterbalanced between subjects) located on a hand-held joystick. Instructions were given to maintain gaze on the fixation spot for the duration of each trial block. The subjects were also told that the arrow cue predicted the most likely location of the subsequent target letter and that, by shifting their covert attention (but not their eyes) to the cued location, they could maximize the speed and accuracy of their performance.

Trials with anticipatory $(<150 \mathrm{msec})$ and delayed $(>1,500 \mathrm{msec})$ responses and trials that included a response $(>2,000 \mathrm{msec})$ from the previous trial were not included in the response times (RTs) reported below. Accuracy and speed of response were equally emphasized to the subjects. The target letter occurred at the cued location with .73 probability and at the noncued location with .27 probability. Across both trial types, the target letters $\mathrm{A}$ and $\mathrm{H}$ occurred with equal probability, Each experimental block contained 60 trials and was approximately $2.7 \mathrm{~min}$ in duration. The subjects were run in 10 blocks in each perceptual load condition, with the order of whether the first 10 blocks were low or high load counterbalanced between subjects. For the ERPs, this yielded approximately 220 valid trials and 80 invalid trials per condition. In the high-load condition for each subject, the difference in gap size between the $\mathrm{A}$ and $\mathrm{H}$ was adjusted as necessary between blocks in order to achieve about a $75 \%$ correct discrimination performance level across cued and uncued trials.

Electrophysiological recording. Scalp potentials were recorded using tin electrodes mounted in a custom Electro-Cap International cap. Electrodes were located at sites FP1, FP2, F3, F4, C3, C4, P3, $\mathrm{P} 4, \mathrm{O} 1, \mathrm{O} 2, \mathrm{~F} 7, \mathrm{~F} 8, \mathrm{~T} 3, \mathrm{~T} 4, \mathrm{~T} 5, \mathrm{~T} 6, \mathrm{CZ}, \mathrm{FZ}$, and PZ of the Interna- tional 10-20 System. In addition, electrodes were located at 10 nonstandard sites: $\mathrm{OZ}$ (midway between $\mathrm{O} 1$ and $\mathrm{O} 2$ ), $\mathrm{POZ}$ (midway between $\mathrm{OZ}$ and $\mathrm{PZ}$ ), OL and OR (midway between $\mathrm{T} 5$ and $\mathrm{O1}$, and T6 and $\mathrm{O} 2$, respectively), $\mathrm{P} 1$ and $\mathrm{P} 2$ (midway between $\mathrm{P} 3$ and $\mathrm{PZ}$, and $\mathrm{P} 4$ and $\mathrm{PZ}$, respectively), $\mathrm{P} 5$ and $\mathrm{P} 6$ (midway between T5 and $\mathrm{P} 3$, and $\mathrm{T} 6$ and $\mathrm{P} 4$, respectively), and $\mathrm{PO} 1$ and $\mathrm{PO} 2$ (midway between $\mathrm{O} 1$ and $\mathrm{P} 1$, and $\mathrm{O} 2$ and $\mathrm{P} 2$, respectively). Vertical eye movements and blinks were recorded with an electrode located below the right eye, and an additional electrode channel was recorded from the right mastoid to be used for later re-referencing of the data (see below). All of these electrode channels were recorded with reference to the left mastoid. Horizontal eye movements were recorded from an electrode on the left outer canthus referenced to an electrode on the right outer canthus.

All electroencephalographic (EEG) and electrooculographic (EOG) activity was amplified with a bandpass of $0.1-100 \mathrm{~Hz}$ (halfamplitude cutoffs), digitized on line at a sampling rate of 256 samples per second, and stored on hard disk. Off line, computerized artifact rejection was used to eliminate trials during which large eye movements $\left(>1^{\circ}\right)$, blinks, muscle potentials, or amplifier blocking occurred. EOGs were then computer averaged after time locking to the onset of the left versus right arrow cue and were examined for any small residual systematic deviations of eye position $\left(<1^{\circ}\right)$, none of the subjects showed any such tendency. Because trials containing large eye movements were excluded from analysis and the subjects were screened for small systematic movements, the data reflect only trials in which the eyes remained at fixation. As a result of these stringent controls, eye-movement contamination can be reliably eliminated as a causal explanation for the effects of attention reported below (for details on EOG calibration, see Mangun \& Hillyard, 1991, Experiment 4). For each subject, ERPs were averaged into epochs beginning $1,500 \mathrm{msec}$ before stimulus onset and continuing for 3,000 msec. Subsequently, all ERPs were algebraically re-referenced to the average of the left and right mastoid signals and were filtered with a low-pass Gaussian filter (a Gaussian impulseresponse function with a standard deviation of $8 \mathrm{msec}$, and a halfamplitude cutoff of $10 \mathrm{~Hz}$ ) to eliminate high-frequency artifacts in the waveforms. The resulting ERPs were then used for producing the grand-averaged waveforms presented below.

Analyses. Omnibus repeated measures analyses of variance (ANOVAs) were performed on RTs, percent correct scores, and the mean amplitudes of the $\mathrm{PI}$ and N1 ERP components recorded at electrode sites OL/OR and T5/T6. These electrodes were chosen for analysis because the sensory-evoked $\mathrm{P} 1$ and $\mathrm{N} 1$ are maximal at these sites (see Heinze, Mangun, et al., 1994). For each subject, 
mean amplitudes of the PI and NI were computed over a 50-msec latency window centered approximately on the components' peak latency in the grand-averaged waveforms. Because the Pl and N1 have different onset latencies in the hemisphere contralateral versus ipsilateral to the visual field of the ERP-eliciting stimulus (Clark et al., 1995; Clark \& Hillyard, 1996), separate 50-msec time windows (reported in the tables below) were established for the contralateral versus ipsilateral $\mathrm{P} 1$ and $\mathrm{N} 1$ components. The baseline for these measurements was the mean voltage for the 100 -msec interval prior to stimulus onset. For RT and percent correct, the omnibus ANOVA factors were visual field of target (left vs. right), perceptual load (low vs. high), and location expectancy (target at cued vs. uncued location). These factors were also included in the ERP analyses, along with hemisphere of recording (contralateral vs. ipsilateral) and electrode site (OL/OR vs. T5/T6). Separate ANOVAs were also performed within each load condition in order to test whether significant expectancy effects had occurred within a given load condition.

\section{Results}

Behavioral performance. Mean RTs and percent correct scores as a function of expectancy (cued vs. uncued target) and perceptual load (low vs. high) can be seen in Table $1 .{ }^{1}$ For RT, there were significant main effects of expectancy $[F(1,10)=30.54, p<.001]$ and perceptual load $[F(1,10)=112.62, p<.001]$. For percent correct, there was a significant main effect of perceptual load $[F(1,10)=71.80, p<.001]$, but no main effect of expectancy $[F(1,10)=0.68]$. There were no perceptual load $\times$ expectancy interactions for either measure (both $F_{\mathrm{S}}<$ 0.41 ).

Event-related potentials. The contralateral and ipsilateral Pl and N1 ERP components from lateral occipital electrodes OL/OR and T5/T6 can be seen in Figure 2, as a function of expectancy and load condition. The mean amplitudes of these ERP components are reported in Table 2.

PI component. The amplitude of the P1 was slightly larger overall for cued targets than for uncued targets, and this effect was found to increase with perceptual load. In the omnibus ANOVA, while there were no main effects of expectancy or perceptual load (both $F_{\mathrm{S}}<2.3$ ), there was an expectancy $\times$ load interaction $[F(1,11)=5.92$, $p<.05] .{ }^{2}$ Separate ANOVAs within each load condition confirmed this interaction, showing a main effect of expectancy only when load was high $[F(1,11)=6.13, p<$ $.05]$. Hemispheric asymmetries were also found in the $\mathrm{Pl}$ attention effect, with an expectancy $\times$ hemisphere of recording interaction $[F(1,11)=30.11, p<.0005]$ in the omnibus ANOVA and an expectancy $\times$ hemisphere interaction when load was low $[F(1,11)=11.52, p<.01]$

Table 1

Mean RTs (in Milliseconds) and Percent Correct Scores, and Their Standard Deviations, for Cued and Uncued Targets in Experiment 1 as a Function of Perceptual Load

\begin{tabular}{|c|c|c|c|c|c|c|c|c|}
\hline \multirow{3}{*}{$\begin{array}{l}\text { Perceptual } \\
\text { Load }\end{array}$} & \multicolumn{4}{|c|}{ RT } & \multicolumn{4}{|c|}{ Percent Correct } \\
\hline & \multicolumn{2}{|c|}{ Cued } & \multicolumn{2}{|c|}{ Uncued } & \multicolumn{2}{|c|}{ Cued } & \multicolumn{2}{|c|}{ Uncued } \\
\hline & $M$ & $S D$ & $M$ & $S D$ & $M$ & $S D$ & $M$ & $S D$ \\
\hline Low & 454 & 74 & 488 & 69 & 98.7 & 1 & 98.5 & 1 \\
\hline High & 622 & 98 & 657 & 87 & 73.8 & 8 & 71.9 & 13 \\
\hline
\end{tabular}

and when load was high $[F(1,11)=30.20, p<.0001]$. While these findings reveal a larger ipsilateral versus contralateral expectancy effect, the key result is that, overall, perceptual load increased the size of the expectancy effect in the P1.

N1 component. In comparison with the $\mathrm{P} 1$, the $\mathrm{N} 1$ was only slightly affected by perceptual load. In the omnibus ANOVA, there were no main effects of expectancy or perceptual load (both $F \mathrm{~s}<0.5$ ), but there was a significant hemisphere $\times$ expectancy $\times$ load $\times$ interaction $[F(1,11)$ $=13.26, p<.005]$, suggesting that an expectancy effect over ipsilateral scalp regions may have been present when load was high. This conclusion was supported by ANOVAs within each load condition, which revealed a significant expectancy $\times$ hemisphere interaction only when load was high $[F(1,11)=6.32, p<.05]$. Although statistically significant, the magnitude of this effect was relatively small, as can be seen in Figure 2.

\section{Discussion}

Did perceptual load modulate spatial selection in early visual cortex? The $\mathrm{P} 1$ showed an interaction between perceptual load and location expectancy, with an expectancy effect in the high-load condition that was absent in the low-load condition. The P1 data thus indicate that perceptual load was able to modulate spatial selection at relatively early stages of information processing in cortex. However, the N1 data were less clear, showing only a modest effect of perceptual load on location expectancy, an interaction that was limited to a small effect in the ipsilateral N1. In terms of behavioral performance, although there was a sizable main effect of expectancy, the RT data failed to show any interaction between load and expectancy.

The negative ERP results from the low-load condition replicate the pattern observed by Eimer (1994), who found no P1 or N1 modulations using a comparable letter discrimination task. However, even in the high-load condition of Experiment 1, the magnitude of the attention effects were relatively small, relative to those of both Luck et al. (1994) and Mangun and Hillyard (1991). Thus, the ERP data suggest that the subjects may not have been maximally allocating their attentional resources to the cued location during the high-load condition. Given that very large modulations of the $\mathrm{P} 1$ and $\mathrm{N} 1$ can occur in cuing paradigms, a likely explanation for the results of Experiment 1 is that our high-load condition was not sufficient to fully engage selection at the cortical loci underlying the P1 and N1. Presumably, more perceptually demanding targets would yield greater attention effects in both ERP components. To test this prediction, a second cuing experiment was performed.

\section{EXPERIMENT 2}

Mangun and Hillyard (1990) have argued that early attentional selection is more likely to be engaged when successful target processing depends on adequate sensory 
$|P S|$
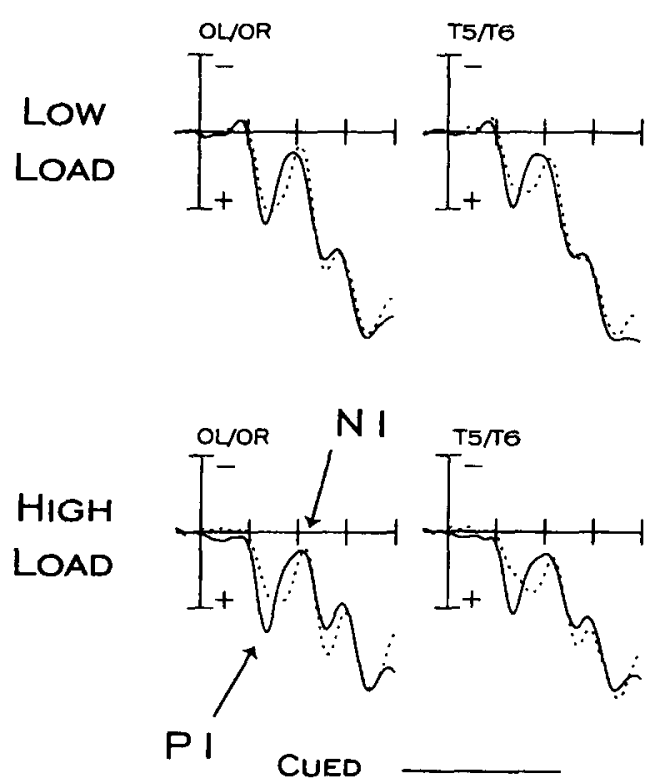

UNCUED
CONTRA
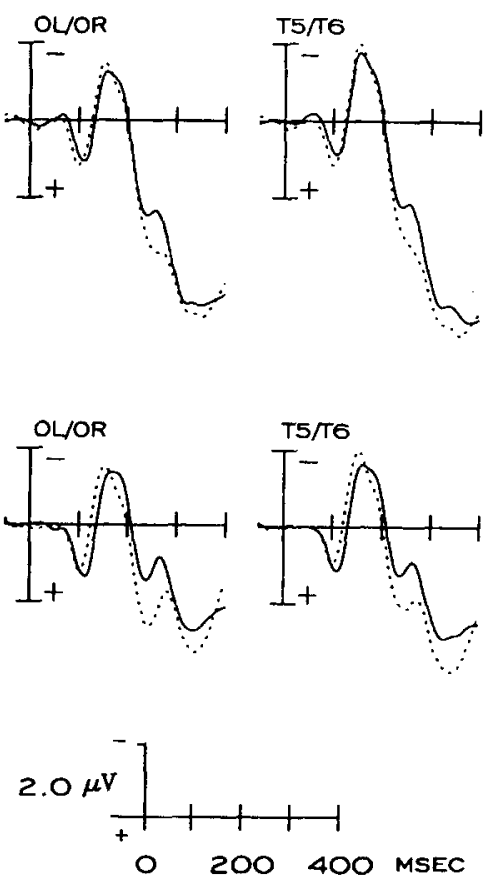

Figure 2. The P1 and N1 ERP components from Experiment 1, averaged over the 12 subjects, as a function of expectancy condition (cued vs. uncued) and perceptual load (low vs. high). The ERPs are collapsed for visual field and are shown as a function of whether the target was in the visual field contralateral or ipsilateral to the hemisphere of recording (see Method section). The P1 and N1 components are labeled in the lower left ERP plot. Note that the expectancy effect in the P1 increases with perceptual load.

gain, such as when target information is relatively poor. Using targets that are perceptually degraded-or signal data-limited (Norman \& Bobrow, 1975) - may be one way in which to increase perceptual load and thus increase the magnitude of the Pl and N1 attention effects (cf. Johnston, McCann, \& Remington, 1995, 1996). Taking this approach to design a new high-load condition in Experiment 2 , two changes were made to perceptually degrade the targets relative to the low-load condition of Experiment 1 . First, the target duration was reduced. Second, a mask was presented at the target location immediately following target offset (see Luck et al., 1994). If the target duration is viewed as "signal," and the mask duration is viewed as "noise," this manipulation of load represents a decrease in the target signal-to-noise ratio relative to the low-load condition (i.e., all target, no mask), which remained unchanged from Experiment 1. Using this manipulation of perceptual load, we again examined the influence of perceptual load on early spatial selection.

\section{Method}

Subjects. Fourteen members ( 7 females, 7 males) of the University of California, Davis, community between the ages of 18 and 28 years were recruited as paid subjects. All subjects were righthanded and had normal or corrected-to-normal vision. None had participated in Experiment 1.
Procedure and Stimuli. All methods and stimuli were identical to those in Experiment 1, with the following exceptions. The target letters used in both were the same as those used in the low-load condition of Experiment 1 (i.e., "A" and " $H$ "). However, in the highload condition of Experiment 2, the target letters were presented for shorter durations and were immediately masked at offset (see Figure 3 ). The mask consisted of a set of randomly oriented white lines of various lengths, $0.06^{\circ}$ thick, contained within a $1^{\circ}$ square area. The mask onset coincided with the target offset; summed together, the duration of the target and mask was $102 \mathrm{msec}$. Within this $102 \mathrm{msec}$, the ratio of time the target was present relative to the mask was varied between trial blocks (depending on subject performance) to ensure that performance was approximately $75 \%$ correct for each subject, as in Experiment 1 . The ratios of target/mask durations used (in milliseconds) were 17/85, 34/68, and 51/51. All recordings and analyses were identical to those of Experiment 1. The subjects were run in a total of 10 blocks of trials in each of the two load conditions, but the load condition was switched after 5 blocks, with order of blocks (low load first vs. high load first) counterbalanced between subjects.

\section{Results}

Behavioral performance. Mean RTs and percent correct scores are reported in Table 3 . The behavioral data replicated the pattern from Experiment 1. For RT, there were significant main effects of expectancy $[F(1,13)=$ $6.57, p<.05]$ and load $[F(1,13)=36.33, p<.001]$. For percent correct, there were also significant main effects of 
Table 2

Mean Amplitudes $( \pm S E)$ of the P1 and N1 ERP Components

in Experiment 1 for Cued and Uncued Targets as a

Function of Load and Hemisphere of Recording (Contralateral vs. Ipsilateral)

\begin{tabular}{|c|c|c|c|c|c|c|c|c|c|}
\hline \multirow[b]{3}{*}{ Electrode } & \multirow[b]{3}{*}{ Load } & \multicolumn{4}{|c|}{ Contralateral } & \multicolumn{4}{|c|}{ Ipsilateral } \\
\hline & & \multicolumn{2}{|c|}{ Cued } & \multicolumn{2}{|c|}{ Uncued } & \multicolumn{2}{|c|}{ Cued } & \multicolumn{2}{|c|}{ Uncued } \\
\hline & & $M$ & $S E$ & $M$ & $S E$ & $M$ & $S E$ & $M$ & $S E$ \\
\hline \multicolumn{10}{|c|}{ PI ERP } \\
\hline OL/OR & Low & 0.46 & 0.29 & 0.71 & 0.30 & 1.82 & 0.27 & 1.53 & 0.3 \\
\hline & High & 0.83 & 0.29 & 0.74 & 0.30 & 2.03 & 0.33 & 1.39 & 0.3 \\
\hline \multirow[t]{2}{*}{$\mathrm{T} 5 / \mathrm{T} 6$} & Low & 0.34 & 0.23 & 0.62 & 0.30 & 1.42 & 0.27 & 1.06 & 0.30 \\
\hline & High & 0.65 & 0.24 & 0.54 & 0.25 & 1.59 & 0.28 & 0.95 & 0.35 \\
\hline \multicolumn{10}{|c|}{ NI ERP } \\
\hline \multirow[t]{2}{*}{ OL/OR } & Low & -0.92 & 0.32 & -1.03 & 0.33 & 0.75 & 0.40 & 0.88 & 0.3 \\
\hline & High & -0.74 & 0.34 & -1.10 & 0.33 & 0.65 & 0.38 & 1.13 & 0. \\
\hline \multirow[t]{2}{*}{ T5/T6 } & Low & -1.43 & 0.28 & -1.52 & 0.24 & 0.76 & 0.34 & 0.99 & 0.3 \\
\hline & High & -1.15 & 0.32 & -1.51 & 0.29 & 0.66 & 0.34 & 1.19 & 0.41 \\
\hline
\end{tabular}

Note-Time windows (in milliseconds) were 70-120 (contra P1), 110-160 (ipsi PI), 130-180 (contra N1), and 175-225 (ipsi N1).

expectancy $[F(1,13)=4.63, p<.05]$ and load $[F(1,13)=$ $104.05, p<.001]$. However, there were no expectancy $\times$ load interactions in either measure (both $F \mathbf{s}<1$ ).

Event-related potentials. The contralateral and ipsilateral P1 and N1 ERP components from lateral occipital electrodes OL/OR and T5/T6 can be seen in Figure 4 as a function of expectancy and load condition. The mean amplitudes of these ERPs are reported in Table 4.

Pl component. For the $\mathrm{P} 1$, there was a significant main effect of expectancy in the omnibus ANOVA $[F(1,13)=$ $10.35, p<.01]$ and a marginal interaction between expectancy and hemisphere of recording $[F(1,13)=4.31$,

\section{HIGH LOAD TRIAL}

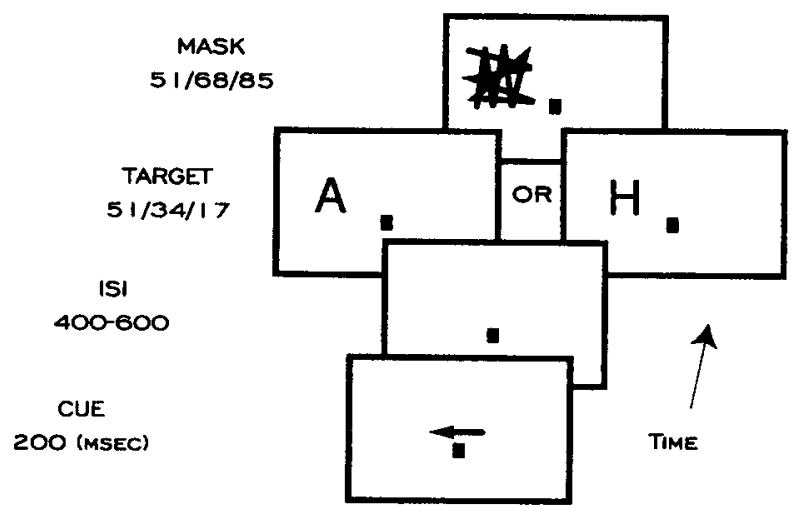

Figure 3. Sequence and timing of stimulus events presented on each high-load trial of Experiment 2. The low-load trials in Experiment 2 were identical to the low-load trials shown in Figure 1. The intertrial interval was 2,000 msec. Stimuli are drawn in reverse contrast to that used in the actual experiment and are not to scale. A valid trial to the left is shown. The relative target and mask durations were varied in order to maintain subject performance level around $75 \%$ correct, but, together, the duration of the target/mask complex always totaled $102 \mathrm{msec}$ (see text). This high-load design was also used in Experiment 3. $p<.06]$; no other main effects or interactions were significant (all $F$ s $<2.4$ ). Separate ANOVAs within each load condition showed significant expectancy effects when load was low $[F(1,13)=7.10, p<.05]$ and when load was high $[F(1,13)=6.37, p<.05]$. Thus, although robust expectancy effects were found in the Pl, perceptual load had no modulatory influence on the magnitude of these effects.

Nl component. For the $\mathrm{Nl}$, perceptual load was found to modulate spatial selection. This was shown in the omnibus ANOVA, where there was an expectancy $\times$ load interaction $[F(1,13)=11.07, p<.01]$, along with main effects of both expectancy $[F(1,13)=6.03, p<.05]$ and load $[F(1,13)=10.56, p<.01]$. ANOVAs within each load condition confirmed the effect of perceptual load on selection, revealing a main effect of expectancy only when load was high $[F(1,13)=10.64, p<.01]$.

\section{Discussion}

In Experiment 2, a load $\times$ expectancy interaction was found in the $\mathrm{N} 1$, indicating an affect of perceptual load on spatial selection in extrastriate visual cortex. However, for the Pl, although significant expectancy effects occurred in both load conditions, there was no expectancy $\times$ load interaction. Similarly, the RT data again failed to show an effect of load on expectancy (an issue addressed in the General Discussion section). Nevertheless, the $\mathrm{N} 1$ data from Experiment 2 and the $\mathrm{P} 1$ data from Experiment 1 provide direct electrophysiological support for the proposal - based on behavioral data - that perceptual load can affect spatial selection at relatively early, perceptual-level processing stages (Lavie \& Tsal, 1994).

Given the identical stimuli in the low-load conditions of Experiments 1 and 2, why did the P1 show an expectancy effect in the latter experiment but not the former? One possibility is that the absence of an attention effect in the low-load condition of Experiment 1 may have been 
Table 3

Mean RTs (in Milliseconds) and Percent Correct Scores, and Their Standard Deviations, for Cued and Uncued Targets in Experiment 2 as a Function of Perceptual Load

\begin{tabular}{|c|c|c|c|c|c|c|c|c|}
\hline \multirow{3}{*}{$\begin{array}{l}\text { Perceptual } \\
\text { Load }\end{array}$} & \multicolumn{4}{|c|}{ RT } & \multicolumn{4}{|c|}{ Percent Correct } \\
\hline & \multicolumn{2}{|c|}{ Cued } & \multicolumn{2}{|c|}{ Uncued } & \multicolumn{2}{|c|}{ Cued } & \multicolumn{2}{|c|}{ Uncued } \\
\hline & $M$ & $\overrightarrow{S D}$ & $M$ & $\overrightarrow{S D}$ & $\bar{M}$ & $\overline{S D}$ & $M$ & $S D$ \\
\hline Low & 466 & 89 & 526 & 177 & $98 . \overline{7}$ & 1 & 96.7 & 7 \\
\hline High & 615 & 111 & 663 & 142 & 76.0 & 8 & 74.4 & 8 \\
\hline
\end{tabular}

anomalous; however, Eimer (1994) also failed to find P1 (and N1) attention effects under similar low-load conditions. As a consequence, the issue must focus on why the $\mathrm{P} 1$ expectancy effect arose in the low-load condition of Experiment 2. For example, the subjects in Experiment 2 may have simply been better at allocating their attention to the cued location-independent of load-relative to the subjects in Experiment 1. However, a more plausible alternative may be that, in Experiment 2, there was a greater influence of the high-load condition on the attentional allocation strategies employed during the low-load trials. This possibility is supported by the overall greater magnitude of the $\mathrm{Pl}$ and $\mathrm{N} 1$ expectancy effects in the high-load condition of Experiment 2, relative to the highload condition of Experiment $1 .^{3}$

While the above scenario can explain why Pl expectancy effects arose when load was low in Experiment 2, why was the $\mathrm{N} l$ not affected in a similar manner? Two lines of data suggest the possibility that, in terms of attentional resources, the N1 may have larger capacity limits than the P1. First, in both Experiment 1 and Experiment 2, there was greater evidence for attention-related modulations in the P1 than in the N1. With smaller capacity limits for engaging early selection, the P1 would be initially more sensitive to manipulations of both perceptual load and location expectancy. In contrast, with larger capacity limits, the N1 would require a greater concentration of resources at the cued location before showing signs of an expectancy effect (see also Eimer, 1994; Mangun \& Hillyard, 1991). Second, it has been argued that the PI and N1 may index different aspects of spatial selection within extrastriate visual cortex (e.g., Hillyard, Vogel, \& Luck, 1998; Luck, 1995; Luck et al., 1994). A difference in capacity limits might therefore be explained by differences in the underlying processing functions reflected in the respective ERP components. To examine possible capacity differences between the $\mathrm{P} 1$ and $\mathrm{N} 1$, a third and final experiment was performed.

\section{EXPERIMENT 3}

If the capacity limits of the $\mathrm{Nl}$ are greater than those of the $P 1$, then, even when increasing attentional resources will no longer affect the $\mathrm{P} 1$, there should continue to be attention-related modulations in the $\mathrm{N} 1$. Although the
$|P S|$
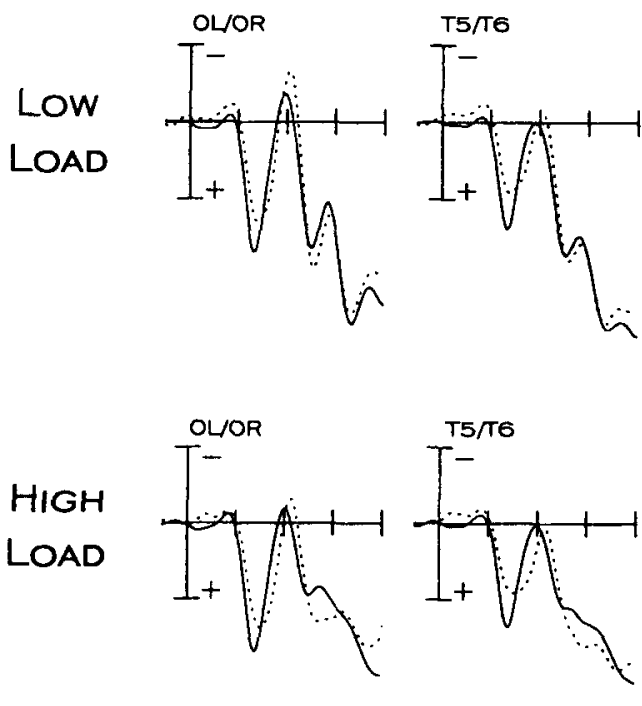

CUED

UNCUED

\section{CONTRA}
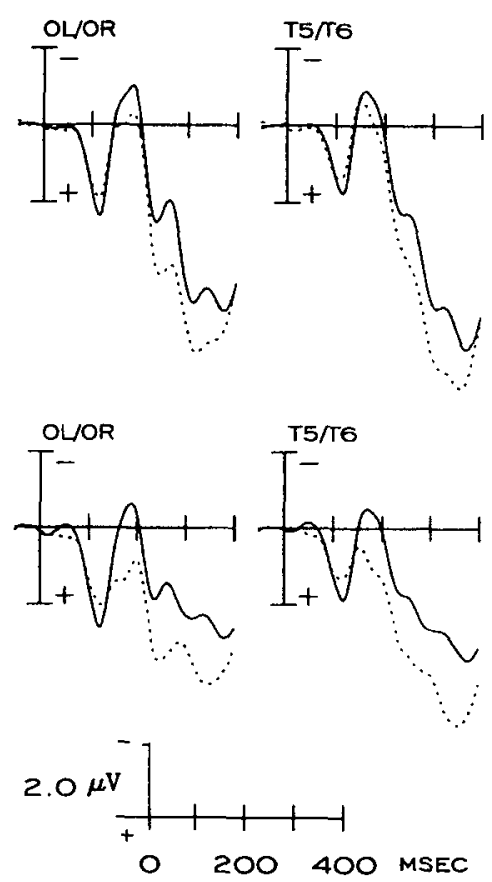

Figure 4. The P1 and N1 ERP components from Experiment 2, averaged over the 14 subjects, as a function of expectancy condition (cued vs. uncued) and perceptual load (low vs. high). The ERPs are collapsed for visual field and are shown as a function of whether the target was in the visual field contralateral or ipsilateral to the hemisphere of recording. Note that the expectancy effect in the $\mathrm{N} 1$ increases with perceptual load. 
Table 4

Mean Amplitudes $( \pm S E)$ of the P1 and N1 ERP Components in Experiment 2 for Cued and Uncued Targets as a Function of Load and Hemisphere of Recording (Contralateral vs. Ipsilateral)

\begin{tabular}{|c|c|c|c|c|c|c|c|c|c|}
\hline \multirow[b]{3}{*}{ Electrode } & \multirow[b]{3}{*}{ Load } & \multicolumn{4}{|c|}{ Contralateral } & \multicolumn{4}{|c|}{ Ipsilateral } \\
\hline & & \multicolumn{2}{|c|}{ Cued } & \multicolumn{2}{|c|}{ Uncued } & \multicolumn{2}{|c|}{ Cued } & \multicolumn{2}{|c|}{ Uncued } \\
\hline & & $M$ & $S E$ & $M$ & $S E$ & $M$ & $S E$ & $M$ & $S E$ \\
\hline \multicolumn{10}{|c|}{ P1 ERP } \\
\hline $\mathrm{OL} / \mathrm{OR}$ & Low & 1.57 & 0.31 & 1.37 & 0.36 & 2.60 & 0.37 & 1.99 & 0.36 \\
\hline \multirow{3}{*}{$\mathrm{T} 5 / \mathrm{T} 6$} & High & 1.55 & 0.26 & 1.34 & 0.33 & 2.46 & 0.33 & 1.82 & 0.30 \\
\hline & Low & 1.11 & 0.31 & 0.99 & 0.38 & 2.05 & 0.35 & 1.37 & 0.30 \\
\hline & High & 1.10 & 0.25 & 0.96 & 0.31 & 1.85 & 0.30 & 1.19 & 0.26 \\
\hline \multicolumn{10}{|c|}{ N1 ERP } \\
\hline \multirow[t]{2}{*}{ OL/OR } & Low & -0.50 & 0.34 & 0.02 & 0.48 & -0.13 & 0.28 & -0.42 & 0.32 \\
\hline & High & 0.22 & 0.42 & 1.40 & 0.62 & 0.08 & 0.30 & 0.47 & 0.29 \\
\hline \multirow[t]{2}{*}{ T5/T6 } & Low & -0.69 & 0.33 & -0.36 & 0.45 & 0.37 & 0.24 & 0.21 & 0.33 \\
\hline & High & -0.21 & 0.39 & 0.73 & 0.57 & 0.28 & 0.28 & 0.79 & 0.29 \\
\hline
\end{tabular}

Note-Time windows (in milliseconds) were 80-130 (contra P1), 110-160 (ipsi Pl), 140-190 (contra N1), and 175-225 (ipsi N1).

high-load stimuli in Experiment 2 were designed to be perceptually demanding and required that attentional resources be focused on the cued location, some attentional resources may have still been strategically allocated to the uncued location in order to facilitate responding to targets presented there (see, e.g., Chastain, Cheal, \& Lyon, 1996). As a result, maximizing locational expectancy by cuing targets with 1.0 probability may allow all resources to be fully allocated to the cued location. In Experiment 3, we replicated the high-load condition from Experiment 2, in which targets were presented at the cued location with approximately .75 probability. This condition was compared with a second expectancy condition, in which targets were presented at the cued location with 1.0 probability. If the capacity limits of the $\mathrm{N} 1$ are larger than those of the P1, only the $\mathrm{N} 1$ should show a change in amplitude between expectancy conditions. ${ }^{4}$

\section{Method}

Twelve people ( 6 females, 6 males) between the ages of 18 and 30 years served as paid subjects in Experiment 3. All subjects had normal or corrected-to-normal vision. One subject had participated in Experiment 1, and 1 subject had participated in Experiment 2. Experiment 3 differed from Experiment 2 in two ways. First, perceptual load was held constant at the high-load level used in Experiment 2 (i.e., all targets were masked). Second, two levels of expectancy were used, where the cues were .75 and 1.0 predictive of the target location, with the order of expectancy conditions counterbalanced between subjects. All other details of Experiment 3 were similar to Experiment 2, except that separate ANOVAs were performed to compare the 1.0 versus .75 cued targets and the .75 versus uncued targets.

\section{Results and Discussion}

Behavioral performance. Mean RTs and percent correct scores are reported in Table 5. Comparing the 1.0 cued targets with the .75 cued targets, the 15 -msec difference in RT was not significant $[F(1,11)=2.57, p>$ $.10]$, but the difference in percent correct was marginally significant $[F(1,11)=4.69, p<.06]$. In contrast, comparing the .75 cued targets with the uncued targets showed main effects of expectancy in both RT $[F(1,11)=42.30, p<.0001]$ and percent correct $[F(1,11)=12.85, p<.005]$, a pattern consistent with the behavioral data from Experiment 2 .

Event-related potentials. The contralateral and ipsilateral Pl and N1 ERP components can be seen in Figure 5 , as a function of expectancy condition ( 1.0 cued, .75 cued, and uncued). The mean amplitudes of these ERPs are reported in Table 6.

Pl component. The P1 showed no modulation when comparing the 1.0 cued targets and the .75 cued targets $(F<1.0)$. However, when comparing the .75 and uncued targets, the $P 1$ data replicated the pattern from the highload condition of Experiment 2, showing a significant effect of expectancy $[F(1,11)=10.56, p<.01]$.

NI component. The N1 was found to increase in amplitude when comparing 1.0 and .75 cued targets, showing a main effect of expectancy $[F(1,11)=10.43, p<.01]$. When comparing the .75 and uncued targets, the N1 data replicated the $\mathrm{N} 1$ pattern from the high-load condition of Experiment 2, showing a main effect of expectancy in this condition as well $[F(1,11)=5.52, p<.05]$.

The results of Experiment 3 support the assumption that the capacity limits of the NI are larger than the capacity limits of the $\mathrm{P} 1$. That is, the increase in attentional

Table 5

Mean RTs (in Milliseconds) and Percent Correct Scores, and Their Standard Deviations, for Targets in Experiment 3 as a Function of Cue (or Expectancy) Condition

\begin{tabular}{|c|c|c|c|c|}
\hline \multirow{2}{*}{$\begin{array}{c}\text { Cue } \\
\text { Condition }\end{array}$} & \multicolumn{2}{|c|}{ RT } & \multicolumn{2}{|c|}{ Percent Correct } \\
\hline & $\vec{M}$ & $\overline{S D}$ & $M$ & $\overline{S D}$ \\
\hline 1.0 & 543 & 65 & 85.7 & 7 \\
\hline .75 & 558 & 76 & 82.3 & 8 \\
\hline Uncued & 607 & 77 & 77.4 & 9 \\
\hline
\end{tabular}


|PSI
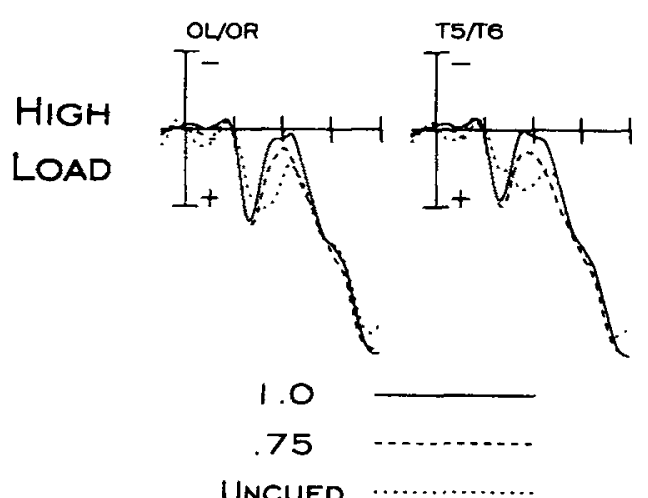

CONTRA

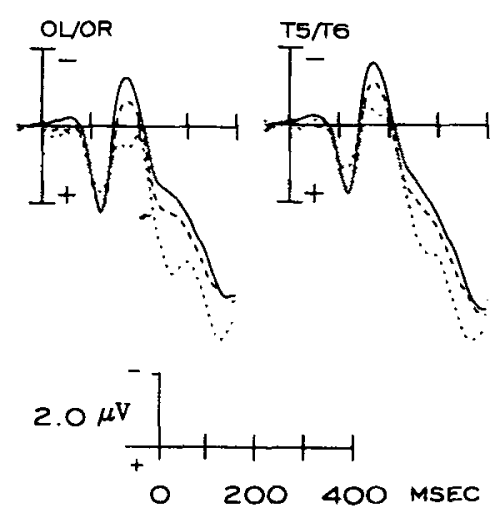

Figure 5. The P1 and N1 ERP components from Experiment 3, averaged over the 12 subjects, as a function of expectancy condition $(1.0, .75$, and uncued) and hemisphere of recording. The ERPs are collapsed for visual field. Note that when comparing 1.0 and .75 cued targets, the $N 1$ shows a significant modulation, whereas the P1 does not.

resource allocation to the cued location under the $1.0 \mathrm{ex}$ pectancy condition produced a further modulation of the $\mathrm{N} 1$, whereas the $\mathrm{Pl}$ amplitude remained unchanged. The pattern of data in the $\mathbf{P l}$ cannot be simply explained by proposing that the $\mathbf{P} 1$ is insensitive to manipulations of location expectancy, because the Pl showed a significant difference in amplitude for the .75 and uncued targets. Rather, the data suggest that the high-load conditions used in Experiments 2 and 3 were sufficient for exceeding the capacity limits of the PI, but not the $\mathrm{N} 1$. The implications of this finding are discussed below.

\section{GENERAL DISCUSSION}

Our study used ERPs to examine whether perceptual load can modulate spatial selection within extrastriate visual cortex. The results from Experiments 1 and 2 showed that increasing the perceptual load of targets in a spatial cuing paradigm led to greater location expectancy effects in both the P1 (Experiment 1) and the N1
(Experiment 2) ERP components. Experiment 3 demonstrated that the $\mathrm{P} 1$ has smaller capacity limits than the $\mathrm{N} 1$, providing an explanation for why the $\mathrm{Pl}$ and $\mathrm{N} 1$ were differentially affected by perceptual load in Experiments $\mathrm{l}$ and 2: The $\mathrm{N} I$ was unaffected in Experiment 1 because it was well below capacity limits even when load was high, and the P1 was unaffected in Experiments 2 and 3 because it had exceeded capacity limits even when load was low. Taken together, these results provide direct evidence that perceptual load can affect early, spatial-based selection within extrastriate visual cortex.

While our results support the proposal of Lavie and Tsal (1994) that perceptual load can mediate spatial selection at perceptual-level processing stages, our ERP data suggest that a modification of their model is needed. In particular, Lavie and Tsal argue that perceptual load mediates whether spatial selection will arise in a given task because it determines the spatial allocation of attentional resources. While this view can account for much of the data from distractor paradigms (e.g., Dark et al.,

Table 6

Mean Amplitudes ( $\pm S E$ ) of the P1 and N1 ERP Components in Experiment 3 for Targets as a Function of Cue (or Expectancy) Condition and Hemisphere of Recording (Contralateral vs. Ipsilateral)

\begin{tabular}{|c|c|c|c|c|c|c|c|c|c|c|c|c|}
\hline \multirow[b]{3}{*}{ Electrode } & \multicolumn{6}{|c|}{ Contralateral } & \multicolumn{6}{|c|}{ Ipsilateral } \\
\hline & \multicolumn{2}{|c|}{1.0} & \multicolumn{2}{|c|}{.75} & \multicolumn{2}{|c|}{ Uncued } & \multicolumn{2}{|c|}{1.0} & \multicolumn{2}{|c|}{.75} & \multicolumn{2}{|c|}{ Uncued } \\
\hline & $M$ & $S E$ & $M$ & $S E$ & $M$ & $S E$ & $M$ & $S E$ & $M$ & $S E$ & $M$ & $S E$ \\
\hline \multicolumn{13}{|c|}{ PI ERP } \\
\hline OL/OR & 1.23 & 0.26 & 1.28 & 0.24 & 1.09 & 0.24 & 1.90 & 0.33 & 1.88 & 0.28 & 1.25 & 0.26 \\
\hline $\mathrm{T} 5 / \mathrm{T} 6$ & 0.88 & 0.20 & 0.93 & 0.19 & 0.69 & 0.20 & 1.40 & 0.27 & 1.43 & 0.23 & 0.61 & 0.22 \\
\hline \multicolumn{13}{|c|}{ NI ERP } \\
\hline OL/OR & -0.60 & 0.44 & -0.12 & 0.36 & 0.56 & 0.36 & 0.31 & 0.43 & 0.56 & 0.35 & 1.11 & 0.37 \\
\hline $\mathrm{T} 5 / \mathrm{T} 6$ & -1.17 & 0.39 & -0.71 & 0.34 & -0.35 & 0.34 & 0.17 & 0.38 & 0.59 & 0.33 & 1.07 & 0.35 \\
\hline
\end{tabular}


1985; Kahneman \& Chajczyk, 1983; Lavie, 1995; Lavie \& Cox, 1997; Miller, 1991; Yantis \& Johnston, 1990; see also Wojciulik et al., 1997), other factors besides perceptual load can also contribute to the pattern of attentional resource allocation. For example, in our study, both perceptual load and location expectancy produced spatially based modulations of the P1 and N1, demonstrating that both of these factors are affecting spatial selection at common extrastriate loci. The central point is that spatial selection follows from resource allocation patterns, which, in turn, are subject to a host of variable determinants, including (but not limited to) perceptual load.

\section{ERP Issues}

Our data address two important issues germane to the ERP literature on early spatial selection in vision. First, there has been a discrepancy in the literature between ERP cuing studies that have (e.g., Mangun \& Hillyard, 1991) and have not (e.g., Eimer, 1994) shown attentionrelated modulations in the $\mathrm{P} 1$ and $\mathrm{N} 1$. Toward resolving this conflict, our data suggest that, in cuing paradigms, perceptual load may determine the minimum amount of resources that must be applied to a cued location in order to adequately perform a given task. However, subjects may be able to allocate more than the minimum amount of resources to that location if properly motivated, as suggested by the $P 1$ attention effect in the low-load condition of Experiment 2. This model could explain why Mangun and Hillyard (1991) found an N1 (and a P1) attention effect in a difficult (high-load) bar-height discrimination task, but we did not when using the letter similarity manipulation in Experiment 1 . The subjects in the Mangun and Hillyard study may have allocated a greater amount of resources to the cued location in response to the high-load discrimination task, whereas the subjects in Experiment 1 may have allocated the minimum amount of resources necessary to perform the task. A similar model can also account for Eimer's (1994) failure to find either $\mathrm{N} 1$ or $\mathrm{P} 1$ attention effects in a expectancy-based cuing experiment similar to the low-load condition of Experiment 1: The subjects in Eimer's experiment may have been able to perform the relatively easy letter discrimination task without a large difference in the amount of resources allocated to the cued versus uncued locations. Indeed, the small (9-msec) attention effect in RT reported by Eimer (1994) supports such an interpretation.

Our ERP results also address the issue of functional dissociations between the $\mathrm{Pl}$ and $\mathrm{N} 1$. In particular, it has been suggested that the P1 may be associated with the suppression of information at unattended locations, whereas the N1 may be associated with the facilitation of information at attended locations (e.g., Luck, 1995; Luck et al., 1994). More recently, Hillyard et al. (1998) have expanded this view, arguing that the $\mathrm{N} 1$ attention effect reflects "a limited-capacity discriminative process." If Hillyard et al. are correct, N1 attention effects would be expected under high-load conditions involving discrimination tasks. Our data support such a position, showing that the $\mathrm{Nl}$ attention effect varied as a function of perceptual load in a letter discrimination task (Experiment 2). However, in another spatial cuing study, Luck et al. (1994) showed significant attention-related modulations of the N1 when a simple detection task was employed. Importantly, the targets used by Luck et al. were masked in a similar fashion to the targets in Experiments 2 and 3, suggesting that they had a relatively high level of perceptual load. Taken together, the data thus suggest that a more general interpretation of the NI may be warranted. Specifically, attention-related modulations in the N1 may arise under any conditions of high perceptual load, independent of whether a discrimination task is employed.

\section{Cuing Versus Distractor Data}

Although the ERP data provided direct evidence that perceptual load can increase the amount of attentional resources applied to the cued location in a spatial cuing paradigm, our RT data failed to show a similar pattern. Rather, while robust main effects of both attention and perceptual load were consistently found, the RTs never displayed an interaction between these two factors. These RT results stand in contrast to RT data reported in distractor interference studies, which have shown characteristic evidence that increasing the perceptual load of task-relevant information increases the amount of attentional resources allocated to the location of that information (e.g., Dark et al., 1985; Kahneman \& Chajczyk, 1983; Lavie, 1995). The difficulty of resolving the apparent conflict between our RT and ERP data is further compounded by the proposal of Lavie and Tsal (1994) that these RT patterns in distractor paradigms reflect early attentional selection: If RT patterns can index early selection in relation to the allocation of limited-capacity attentional resources, why did our RT data fail to mirror the pattern seen in the ERPs, which are a direct measure of early selection? Several possibilities exist.

First, like the ERPs, the RT data may reflect evidence of early selection, but the capacity limits of processing indexed by the RTs may have been smaller than the processing indexed by both the Pl and N1 ERP components. In this respect, location expectancy under conditions of low perceptual load could have been sufficient to concentrate enough attentional resources at the cued location such that the capacity limits manifest in the RTs had already been exceeded. As a result, when load was then manipulated by either increasing the target similarity (Experiment 1) or decreasing the target signal-to-noise ratio (Experiment 2), no further modulations of the RT attention effects were observed because the RTs were not sensitive to any further increase in attentional resources at the cued location. However, perceptual load would be expected to produce evidence for early selection in RTs in distractor studies because load would be the only influence on the spatial allocation of attentional resources in those paradigms. 
This position is consistent with the RT data from Experiment 3 , in which RTs to cued targets did not change significantly when location expectancy was increased by eliminating uncued targets from the display. Likewise, Briand and Klein (1987) found no change in RT attention effects when targets were varied along a feature/conjunction continuum in a spatial cuing task. In both cases, cuing subjects to the most likely location of the target was sufficient for allocating the majority of resources to the cued location, and no further modulation of the RT effect was observed. However, positing that both the RTs and the ERPs reflect early selection raises critical issues regarding early selection and the resources underlying such processes. Do the RTs and ERPs measure the same aspect of early selection, but do the RTs simply have a ceiling effect in response to increased resource allocation that is not found in the ERPs? Conversely, are these measures actually reflecting distinct and dissociable components of early selection, where the different components have different capacity limits? Either account would be consistent with both our data and the model proposed by Lavie and Tsal (1994).

On the other hand, it is quite possible that the RT patterns reported here are not reflecting early selection at all. Rather, they may be associated with later, decisionlevel processing stages (e.g., Sperling, 1984; Sperling \& Dosher, 1986). While our data do not rule out this possibility, it would argue against the model proposed by Lavie and Tsal (1994) by raising the possibility that the RT effects reported in distractor studies also reflect later, postperceptual selection mechanisms. One way to examine this possibility would be to measure ERPs in a distractor paradigm while manipulating perceptual load. If the effects summarized by Lavie and Tsal are reflecting later selection, then there should be no changes in the amplitudes of the $\mathrm{Pl}$ and $\mathrm{N} 1$ to target and nontarget stimuli as perceptual load is varied between low and high levels. However, if the RT patterns in distractor paradigms are reflecting early selection, as the load of target items is increased, the Pl and Nl amplitudes should increase for the foveal targets and should decrease for the parafoveal nontargets. We are currently examining these competing hypotheses.

\section{REFERENCES}

Alho, K., Woods, D. L., Algazi, A., \& Nä̈̈tänen, R. (1992). Intermodal selective attention. II. Effects of attentional load on processing of auditory and visual stimuli in central space. Electroencephalography \& Clinical Neurophysiologv, 82, 356-368.

ANlio-Vento, L., \& Hillyarn, S. A. (1996). Selective attention to the color and direction of moving stimuli: Electrophysiological correlates of hierarchical feature selection. Perception \& Psychophysics, 58, 191-206

Bashinski, H. S., \& Bacharach, V. R. (1980). Enhancement of perceptual sensitivity as the result of selectively attending to spatial locations. Perception \& Psychophusics, 28, 241-248.

Briand, K. A.. \& KLEIN, R. M. (1987). Is Posner's "beam" the same as Treisman's "glue"? On the relation between visual orienting and feature integration theory. Journal of Experimental Psychology: Human Perception \& Performance, 13, 228-241.

Chastain, G., Cheal. M.. \& Lyon. D. R. (1996). Attention and non- target effects in the location-cuing paradigm. Perception \& Psychophysics, 58, 300-309.

Cheal, M., \& Gregory, M. (1997). Evidence of limited capacity and noise reduction with single-element displays in the location-cuing paradigm. Journal of Experimental Psychology: Human Perception \& Performance, 23, 51-71.

Clark, V. P., Fan, S., \& Hillyard, S. A. (1995). Identification of early visual evoked potential generators by retinotopic and topographic analyses. Human Brain Mapping, 2, 170-187.

Clark, V. P., \& Hillrard. S. A. (1996). Spatial selective attention affects early extrastriate but not striate components of the visual evoked potential. Journal of Cognitive Neuroscience, 8, 387-402.

CowAN, N. (1995). Attention and memory: An integrated framework. New York: Oxford University Press.

Dark, V. J., Johnston, W. A., Myles-Worsley, M., \& Farah, M. J. (1985). Levels of selection and capacity limits. Journal of Experimental Psychology: General, 114, 472-497.

Desimone, R., \& DunCAN, J. (1995). Neural mechanisms of selective visual attention. Annual Review of Neuroscience, 18, 193-222.

DowNING, C. J. (1988). Expectancy and visuo-spatial attention: Effects on perceptual quality. Journal of Experimental Psychology: Human Perception \& Performance, 13, 228-241.

DunCaN, J., \& Humphreys, G. W. (1989). Visual search and stimulus similarity. Psychological Review, 96, 433-458.

DunCAN, J., \& Humphreys, G. W. (1992). Beyond the search surface: Visual search and attentional engagement. Journal of Experimental Psychology: Human Perception \& Performance, 18, 578-588.

EAson, R. G. (1981). Visual evoked potential correlates of early neural filtering during selective attention. Bulletin of the Psychonomic Societv, 18, 203-206.

Eason. R. G.. HARTER, M., \& White. C. (1969). Effect of attention and arousal on visually evoked cortical potentials. Physiology \& Behavior, 4. 283-289.

EIMER, M. (1994). "Sensory gating" as a mechanism for visuospatial orienting: Electrophysiological evidence from trial-by-trial cuing experiments. Perception \& Psychophusics, 55, 667-675.

Eimer, M. ( [995). Event-related potential correlates of transient attention shifts to color and location. Biological Psychology, 41, 167-182.

ERIKSEN, C. W., \& ST. JAMES, J. D. (1986). Visual attention within and around the field of focal attention: A zoom lens model. Perception \& Psychophysics, 40, 225-240.

ERIKSEN, C. W., \& YEH, Y.-Y. (1985). Allocation of attention in the visual field. Journal of Experimental Psychology: Human Perception \& Performance, 11, 583-597.

Handy, T. C., Kingstone, A., \& Mangun, G. R. (1996). Spatial distribution of visual attention: Perceptual sensitivity and response latency. Perception \& Psychophysics, 58, 613-627.

Hawkins, H. L., Hillyard, S. A., Luck, S. J., Mouloua, M., DownING, C. J., \& WoODWARD, D. P. (1990). Visual attention modulates signal detectability. Journal of Experimental Psychology: Human Perception \& Performance, 16, 802-811.

Heinze, H.-J., Luck, S. J., Mangun, G. R., \& Hil.lyard, S. A. (1990). Visual event-related potentials index focused attention within bilateral stimulus arrays. I. Evidence for early selection. Electroencephalography \& Clinical Neurophysiology, 75, $511-527$.

Heinze, H.-J., LuCK, S. J., Münte. T. F., Gös, A., Mangun, G. R., \& HilLYARD, S. A. (1994). Attention to adjacent and separate positions in space: An electrophysiological analysis. Perception \& Psychophysics, 56, 42-52.

Heinze, H.-J.. Mangun, G. R., Burchert, W., Hinrichs, H., SCholz, M., Münte. T. F., Gös. A.. Scherg, M.. Johannes, S., Hundeshagen, H., Gazzaniga. M. S., \& Hillyard, S. A. (1994). Combined spatial and temporal imaging of brain activity during visual selective attention in humans. Nature, 372, 543-546.

Hil.LYARD, S. A., \& Münte, T. F. (1984). Selective attention to color and location: An analysis with event-related brain potentials. Perception \& Psychophysics, 36, 185-198.

Hullyard, S. A., VoGel. E. K.. \& LUCK, S. J. (1998). Sensory gain control (amplification) as a mechanism of selective attention: Electrophysiological and neuroimaging evidence. Philosophical Transactions of the Roval Society of London: Series B, 353, 1-14.

Johnston, J. C., MCCANn, R. S., \& Remington, R. W. (1995). Chrono- 
metric evidence for two types of attention. Psychological Science, 6 , 365-369.

Johnston, J. C., McCann, R. S., \& Remington, R. W. (1996). Selective attention operates at two processing loci. In A. F. Kramer, M. G. H. Coles, \& G. D. Logan (Eds.), Converging operations in the study of visual selective attention (pp. 439-458). Washington, DC: APA.

KaHneman, D., \& ChaJCZYK, D. (1983). Tests of the automaticity of reading: Dilution of Stroop effects by color-irrelevant stimuli. Journal of Experimental Psychology: Human Perception \& Performance, 9, 497-509.

Kramer, A. F., \& Spinks, J. (1991). Capacity views of human information processing. In J. R. Jennings \& M. G. H. Coles (Eds.), Handbook of cognitive psychophysiology: Central and autonomic nervous system approaches (pp. 179-249). New York: Wiley.

LABERGE, D. (1995). Attentional processing: The brain's art of mindfulness. Cambridge, MA: Harvard University Press.

LAviE, N. (1995). Perceptual load as a necessary condition for selective attention. Journal of Experimental Psychology: Human Perception \& Performance, 21, 451-468.

LAviE, N., \& Cox, S. (1997). On the efficiency of visual selective attention: Efficient visual search leads to inefficient distractor rejection. Psychological Science, 8, 395-398.

Lavie, N., \& Tsal, Y. (1994). Perceptual load as a major determinant of the locus of selection in visual attention. Perception \& Psychophysics, 56, 183-197.

LuCK, S. J. (1995). Multiple mechanisms of visual-spatial attention: Recent evidence from human electrophysiology. Behavioural Brain Research, 71, 113-123.

Luck, S. J., Hillyard, S, A., Mouloua, M., \& Hawkins, H. L. (1996). Mechanisms of visual-spatial attention: Resource allocation or uncertainty reduction? Journal of Experimental Psychology: Human Perception \& Performance, 22, 725-737.

Luck, S. J., Hillyard, S. A., Mouloua, M., Woldorf, M. G., Clark. V. P., \& HAWKINS, H. L. (1994). Effects of spatial cuing on luminance detectability: Psychophysical and electrophysiological evidence for early selection. Journal of Experimental Psychology: Human Perception \& Performance, 20, 887-904.

Mangun, G. R. (1995). Neural mechanisms of visual selective attention. Psychophysiology, 32, 4-18.

Mangun, G. R., \& Hillyard, S. A. (1990). Allocation of visual attention to spatial locations: Tradeoff functions for event-related brain potentials and detection performance. Perception \& Psychophysics, 47, 532-550.

Mangun, G. R., \& Hillyard, S. A. (1991). Modulation of sensoryevoked brain potentials provide evidence for changes in perceptual processing during visual-spatial priming. Journal of Experimental Psychology: Human Perception \& Performance, 17, 1057-1074.

MangUN, G. R., \& Hillyard, S. A. (1995). Mechanisms and models of selective attention. In M. D. Rugg \& M. G. H. Coles (Eds.), Electrophysiology of mind: Event-related brain potentials and cognition (pp. 40-85). New York: Oxford University Press.

Mangun, G. R., Hopfinger, J. B., Kussmaul, C. L., Fletcher, E., \& HeInZE, H.-J. (1997). Covariations in ERP and PET measures of spatial selective attention in human extrastriate visual cortex. Human Brain Mapping, 5, 273-279.

Miller, J. (1991). The flanker compatibility effect as a function of visual angle, attentional focus, visual transients, and perceptual load: A search for boundary conditions. Perception \& Psychophysics, 49, 270-288.

Moray, N. (1967). Where is attention limited? A survey and a model. Acta Psychologica, 27, 84-92.

Müller, H. J., \& HumPhreYs, G. W. (1991). Luminance-increment detection: Capacity-limited or not? Journal of Experimental Psychology: Human Perception \& Performance, 17, 107-124.

Nä̈̈TÄNEN, R. (1992). Attention and brain function. Hillsdale, NJ: Erlbaum.

Navon, D., \& Gopher, D. (1979). On the economy of the human processing system. Psychological Review, 86, 214-255.

Navon, D., \& Gopher, D. (1980). Task difficulty, resources, and dual- task performance. In R. S. Nickerson (Ed.), Attention and performance VIII (pp. 297-315). Hillsdale, NJ: Erlbaum.

Norman, D. A., \& Bobrow, D. G. (1975). On data-limited and resourcelimited processes. Cognitive Psvchology, 7, 44-64.

PAN, K., \& ERIKSEN, C. W. (1993). Attentional distribution in the visual field during same different judgments as assessed by response competition. Perception \& Psychophysics, 53, 134-144.

PASHLER, H. E. (1998). The psychology of attention. Cambridge, MA: MIT Press.

PoSNER, M. I. (1980). Orienting of attention. Quarterly Journal of Experimental Psychology, 32, 3-25.

SANDERS, A. F. (1990). Issues and trends in the debate on discrete vs. continuous processing of information. Acta Psychologica. 74, 123-167.

ShiU, L., \& PASHLER, H. (1994). Negligible effects of spatial precuing on identification of single digits. Journal of Experimental Psychology: Human Perception \& Performance, 20, 1037-1054.

SpERLING, G. (1984). A unified theory of attention and signal detection. In R. Parasuraman \& D. R. Davies (Eds.), Varieties of attention (pp. 103-181). Orlando, FL: Academic Press.

Sperling, G., \& Dosher, B. A. (1986). Strategy and optimization in human information processing. In K. R. Boff, L. Kaufman, \& J. P. Thomas (Eds.), Handbook of perception and human performance (Vol. 1, pp. 2.1-2.65). New York: Wiley.

van der Molen, M. W., Bashore, T. R., Halliday, R., \& Callaway, E. (1991). Chronopsychophysiology: Mental chronometry augmented by psychophysiological time markers. In J. R. Jennings \& M. G. H. Coles (Eds.), Handbook of cognitive psychophysiology: Central and autonomic nervous system approaches (pp. 9-178). New York: Wiley.

VAN VoORHIS, S., \& HiLlyaRd, S. A. (1977). Visual evoked potentials and selective attention to points in space. Perception \& Psychophysics, 22, 54-62.

Wickens, C. D. (1980). The structure of attentional resources. In R. S. Nickerson (Ed.), Attention and performance VIII (pp. 239-257). Hillsdale, NJ: Erlbaum.

WojciUlik, W., Kanwisher, N., \& Driver, J. (1997, April). Activation of intraparietal sulci in nonspatial visual search. Poster presented at the annual meeting of the Cognitive Neuroscience Society, Boston.

YANTIS, S., \& Johnston. J. C. (1990). On the locus of visual selection: Evidence from focused attention tasks. Journal of Experimental Psychology: Human Perception \& Performance, 16, 135-149.

\section{NOTES}

1. Although 12 subjects were run in Experiment 1, 1 subject's data were lost following ERP averaging but before extraction of behavioral data, due to corruption of the data storage media. As a consequence, the behavioral data reported are for only 11 subjects.

2. The ANOVAs also included factors of visual field of target stimulus (left vs. right) and electrode site (OL/OR vs. T5/T6). However, main effects of and interactions involving these factors do not affect the interpretation of the data we are presenting; thus, for brevity, they are not reported in the results. For similar reasons, main effects of hemisphere are not reported.

3. In addition, counterbalancing procedures differed slightly between Experiments 1 and 2, with three fourths of the low-load trials in Experiment 2 following initial exposure to high-load trials but only half of the low-load trials following initial exposure to the high-load trials in Experiment 1 (across subjects). This may have contributed to the use of highload resource allocation strategies on low-load trials in Experiment 2.

4. This prediction rests on the assumption that, given the use of the high-load targets from Experiment 2, the P1 was at or near capacity limits, whereas the N1 was not. The data from Experiment 2 support this assumption by showing that the $\mathrm{P} 1$ expectancy effect was unchanged by the load manipulation, whereas the $\mathrm{N} 1$ continued to show loadrelated modulations.

(Manuscript received June 17, 1997; revision accepted for publication October $17,1998$. 